\title{
The lymphocyte-to-monocyte ratio: An added value for death prediction in heart failure
}

\author{
N. Silva ${ }^{a, b, c, *}$, P. Bettencourt ${ }^{\text {a,d }}$, J.T. Guimarães b,c,e \\ ${ }^{a}$ Unidade IED Cardiovascular do Porto, Faculdade de Medicina da Universidade do Porto, 4202-451 Porto, Portugal \\ ${ }^{b}$ Departamento de Bioquímica, Faculdade de Medicina da Universidade do Porto, 4202-451 Porto, Portugal \\ ${ }^{c}$ Serviço de Patologia Clínica, Centro Hospitalar São João, 4202-451 Porto, Portugal \\ ${ }^{d}$ Serviço de Medicina Interna, Centro Hospitalar São João, 4202-451 Porto, Portugal \\ ${ }^{e}$ EPIUnit, Instituto de Saúde Pública da Universidade do Porto, 4050-600 Porto, Portugal \\ Received 26 February 2015; received in revised form 18 June 2015; accepted 13 July 2015 \\ Available online 26 July 2015
}

\section{KEYWORDS \\ Leukocyte \\ differential; \\ Lymphocyte-to- \\ monocyte ratio; \\ Heart failure; \\ Death}

\begin{abstract}
Background and aim: Leukocytes and their subpopulation have been long implicated in the progression of the syndrome of heart failure (HF), especially heart infiltration cells. Previous reports have suggested that they can predict worse outcome in patients with HF, and can also affect the function of other cells and myocardial extracellular matrix remodeling process. However, the lymphocyte-to-monocyte ratio (LMR) and its possible value as prognostic marker have not been evaluated.

Methods and results: A total of 390 patients with acute HF were recruited and followed for 6 months. Their total blood count with leukocyte differential was obtained. Two groups were formed according to the endpoints of HF death and optimal cut-off value of LMR, and were compared. A multivariate Cox-regression model was used to establish the prognostic value with the endpoints of $\mathrm{HF}$ and all-cause mortality. Median age of the patients was 78 years and $48.5 \%$ of them were men. No major difference was observed between the clinical characteristics of the two groups. Patients who died of HF had significantly higher values of B-type natriuretic peptide and lower values of LMR. Leukocyte and monocyte counts revealed a multivariate-adjusted risk for both endpoints, whereas relative lymphocyte counts had only significant value for allcause mortality. The multivariate-adjusted hazard ratios for the 6-month HF and all-cause mortality in patients with LMR values $<2.0$ were, respectively, 2.28 (95\% CI: 1.25-4.15) and 2.39 (95\% CI: $1.39-4.10)$.

Conclusion: Our results show that, upon discharge from hospital after an episode of acute HF, a lower value of LMR is independently associated with a higher risk of mortality within 6 months. ( 2015 The Italian Society of Diabetology, the Italian Society for the Study of Atherosclerosis, the Italian Society of Human Nutrition, and the Department of Clinical Medicine and Surgery, Federico II University. Published by Elsevier B.V. All rights reserved.
\end{abstract}

\section{Introduction}

Pathophysiology of heart failure (HF) is no longer regarded as an isolated cardiac entity, but rather an increasingly

\footnotetext{
* Corresponding author. University of Porto, Cardiovascular R\&D Unit, Al. Prof. Hernâni Monteiro, 4200-319 Porto, Portugal. Tel.: +351 912821468.

E-mail address: nunosilva.box@gmail.com (N. Silva).
}

more complex and systemic condition. The types of prognostic factors associated with the risk of HF morbidity and mortality have been increasing [1-3], with a special emphasis on markers associated with inflammation, such as interleukin-6, tumor necrosis factor- $\alpha$, and C-reactive protein (CRP) [4-7]. However, regardless of its pathogenesis, the major causes of HF progression are still ventricular remodeling and fibrosis. It is shown that mechanisms of inflammation may be evident in this maladaptive progression of distinct HF etiologies [8]. Heart infiltration 
cells, including granulocytes, monocytes, macrophages, dendritic cells, mast cells, and T- and B-lymphocytes, can produce and secrete various cytokines, modulating the inflammatory response and affecting the functions of other cells and myocardial extracellular matrix remodeling process $[9,10]$.

As both lymphocytes and monocytes play important roles in HF-related inflammation and remodeling/fibrosis, and considering the heterogeneity of $\mathrm{HF}$, we aim to test if the LMR is also a useful parameter in discriminating the HF patients at a higher risk of mortality.

\section{Methods}

\section{Study population}

We conducted a prospective observational study between January 2009 and December 2010. In this study, patients admitted to the department of internal medicine of a central Portuguese hospital center, with the primary diagnosis of HF, either worsening or de novo HF, were included. However, patients with acute coronary syndromes, with symptoms attributable to causes other than $\mathrm{HF}$, or with no echocardiographic structural or functional cardiac abnormality were excluded from the study.

An echocardiogram was performed in all eligible patients within $72 \mathrm{~h}$ of admission. A comprehensive echocardiographic assessment was performed using a multifrequency matrix probe (Vivid S6, GE Healthcare). The diagnosis of HF was made in accordance with the guidelines of the European Society of Cardiology [11]. All HF etiologies were admitted. Both groups of patients with left ventricular systolic dysfunction (LVSD) and HF with preserved ejection fraction were included in the study. A left ventricular ejection fraction (LVEF) of above $50 \%$ was defined as normal systolic fraction. Treatment decisions, timing of discharge, and discharge medication were at discretion of the attending physician, and the physicians were aware of the ongoing study.

Fasting venous blood samples were collected from all patients between 7 and 8 am on the day of discharge. Clinical and demographic data were collected, and other relevant information was obtained by interview upon the collection of the blood samples. Plasma B-type natriuretic peptide (BNP) was measured by a chemiluminescent immunoassay in the Architect i2000 automated analyzer (Abbott), and serum creatinine and CRP were measured in the automated clinical chemistry Olympus AU5400 analyzer (Beckman Coulter Inc.). Data on hemoglobin level and complete blood count $(\mathrm{CBC})$ with leukocyte differential were obtained in a Sysmex XE-5000 automated blood counter (Sysmex).

Comorbidities were also recorded for each patient. Coronary heart disease was verified with a history of myocardial infarction, history or electrocardiographic evidence of ischemia, or confirmation of coronary angiography. Diabetes mellitus was confirmed with a history of diabetes or the current prescription of either an oral hypoglycemic agent or insulin. Anemia was found to be present when the hemoglobin level was $<13$ and $<12$ g/dL in men and women, respectively. Arterial hypertension was confirmed with the presence of previous diagnosis or evidence of antihypertensive pharmacological treatment. Renal dysfunction was suspected when creatinine levels exceeded $1.5 \mathrm{mg} / \mathrm{dL}$. Alcohol habits of the patients were determined by clinician evaluation. Estimated glomerular filtration rate (EGFR) was calculated by the Cockcroft-Gault equation [12].

Patients were followed up for a period of 6 months after discharge, by means of consultation in the hospitals and/or telephone contact. The obtained endpoints were HF death, including worsening congestion because of progressive pump failure and sudden cardiac death, and all-cause mortality.

It is worth noting that all patients provided written informed consent to participate in the study. The study protocol conformed to the ethical guidelines of the Declaration of Helsinki, and was approved by the local ethics committee.

\section{Statistical analysis}

Continuous variables are presented as median (interquartile range (IQR)) because of the skewed distribution, and categorical variables as counts and proportions. Normality of the variables was determined by the Shapiro-Wilk test.

Patients were divided according to the endpoint of HF death and the optimal cut-off value of LMR. This value was calculated through receiver operating characteristic (ROC) curves and the Youden index. The Youden index is useful in the calculation of the maximum vertical distance or difference between the ROC curve and the diagonal or chance line, which represents the cut-point that optimizes the differentiating ability of the biomarker when sensitivity and specificity are given equal importance. Groups were formed and compared. A chi-squared test was used for the comparison of categorical variables, and a Man$\mathrm{n}$-Whitney test was used for comparing continuous variables once their distribution was skewed.

A univariate Cox-regression analysis was used for the assessment of prognostic power of the variables under study. Variables that were found to be of prognostic significance or known to influence HF prognosis were included in the developed multivariate models. Variables with significant prognostic power in the multivariate models were also divided into groups according to their optimal cut-off values to evaluate their influence on stratification of our patients.

The Kaplan-Meier test was used for estimating the survival function of patients in the 6-month follow-up with both outcomes in study, and according to the cut-off value calculated by the Youden index.

It was considered that $p=0.05$ is statistically significant with a confidence interval of $95 \%$.

Data were stored and analyzed using software packages such as SPSS Statistics 20.0 (SPSS Inc., Chicago, IL, USA) and MedCalc 14.8.1 (MedCalc Software bvba, Ostend, Belgium). 


\section{Results}

This study included 390 patients discharged after hospitalization due to an acute episode of HF. The median age of the patients was 78 years (IQR: $70-84$ ), and $48.5 \%$ of them were men. Ischemic HF etiology was found in $35.4 \%$ of the patients, 58.2\% had systolic HF, and $19.2 \%$ were discharged with a New York Heart Association (NYHA) class of III or IV. Diabetes mellitus and anemia were comorbidities in $43.8 \%$ and $42.8 \%$ of the patients, respectively. Arterial hypertension affected $76.9 \%$ of the patients, and $22.8 \%$ suffered from renal dysfunction. In addition, approximately $50 \%$ of the patients were drinkers, and $36.4 \%$ were current or exsmokers. Characteristics, comorbidities, and results of laboratory assessment of the patients are shown in Table 1. The patients were followed up for 6 months after discharge, during which 51 patients died due to HF among the total 66 deaths. Table 1 also presents the classification of patients based on the endpoint of HF. Patients who died because of HF had significantly higher values of BNP and monocyte counts, whereas hemoglobin levels and relative counts of lymphocytes were significantly reduced. They also presented significantly lower LMR values, and were also less prompt to have chronic arterial hypertension.

Table 2 presents the predictors of 6-month HF mortality and all-cause mortality for our group of patients in a univariate approach. The predictors of HF death were the presence of ischemic etiology of HF, a higher NYHA class, a

Table 1 Patients' demographics, clinical and laboratory characteristics, and discharge medication; Comparison between patients who died due to HF and survivors at 6-month follow-up.

\begin{tabular}{|c|c|c|c|c|}
\hline & $\begin{array}{l}\text { All patients } \\
(n=390)\end{array}$ & $\begin{array}{l}\text { HF death } \\
(n=51)\end{array}$ & $\begin{array}{l}\text { Non-HF death/Survivors } \\
(n=339)\end{array}$ & $\begin{array}{l}p \\
\text { Value }\end{array}$ \\
\hline \multicolumn{5}{|l|}{ Clinical characteristics } \\
\hline Age (years), median (IQR) & $78(70-84)$ & $78(72-86)$ & $77(69-83)$ & 0.101 \\
\hline Male sex, $n(\%)$ & $189(48.5)$ & 29 (56.9) & $160(47.2)$ & 0.205 \\
\hline Ischemic etiology of HF, $n$ (\%) & $138(35.4)$ & $23(45.1)$ & 115 (33.9) & 0.102 \\
\hline Preserved LVSF, $n(\%)$ & $163(41.8)$ & $16(31.4)$ & $147(43.4)$ & 0.110 \\
\hline $\begin{array}{l}\text { NYHA class at discharge } \\
\text { (III \& IV vs. I \& II), } n \text { (\%) }\end{array}$ & $75(19.2)$ & $17(33.3)$ & $58(17.1)$ & 0.005 \\
\hline \multicolumn{5}{|l|}{ Comorbidities } \\
\hline Diabetes mellitus, $n$ (\%) & $171(43.8)$ & $20(39.2)$ & $151(44.5)$ & 0.464 \\
\hline Anemia history, $n$ (\%) & $167(42.8)$ & $26(51.0)$ & $141(41.6)$ & 0.244 \\
\hline Chronic arterial hypertension, $n(\%)$ & $300(76.9)$ & $31(60.8)$ & $269(79.4)$ & 0.007 \\
\hline Chronic renal dysfunction, $n(\%)$ & $89(22.8)$ & $15(29.4)$ & $74(21.8)$ & 0.268 \\
\hline \multicolumn{5}{|l|}{ Smoking habits, $n(\%)$} \\
\hline Current smoker/ex-smoker & $31 / 111(7.9 / 28.5)$ & $0 / 18(0.0 / 35.3)$ & $31 / 93(9.1 / 27.4)$ & 0.059 \\
\hline Alcohol habits, $n(\%)$ & $179(45.9)$ & $22(43.1)$ & $157(46.3)$ & 0.718 \\
\hline \multicolumn{5}{|l|}{ Laboratory at discharge } \\
\hline Hemoglobin (g/dL), median (IQR) & $12.0(10.8-13.5)$ & $11.6(10.4-12.4)$ & $12.1(10.9-13.7)$ & 0.018 \\
\hline GFR (mL/min), median (IQR) & $39.2(28.7-51.9)$ & $33.4(25.6-47.4)$ & $40.2(29.6-53.3)$ & 0.064 \\
\hline \multirow[t]{2}{*}{ BNP (pg/mL), median (IQR) } & 727.1 & 1829.6 & 602.0 & $<0.000$ \\
\hline & (309.0-1353.9) & $(1080.2-2656.0)$ & $(263.2-1208.4)$ & \\
\hline CRP (mg/L), median (IQR) & $12.3(6.3-25.3)$ & $15.7(9.2-30.6)$ & $11.4(6.0-24.9)$ & 0.059 \\
\hline \multicolumn{5}{|l|}{ Leukocytes } \\
\hline Count (cells $/ \mu \mathrm{L})$, median (IQR) & $7215(5808-8633)$ & $7590(6030-9800)$ & $7155(5783-8573)$ & 0.164 \\
\hline \multicolumn{5}{|l|}{ Monocytes } \\
\hline Count (cells $/ \mu \mathrm{L})$, median (IQR) & $580(460-770)$ & $670(520-920)$ & $570(448-760)$ & 0.012 \\
\hline Relative count (\%), median (IQR) & $8.5(6.8-10.3)$ & $8.7(7.1-11.0)$ & $8.5(6.7-10.3)$ & 0.314 \\
\hline \multicolumn{5}{|l|}{ Lymphocytes } \\
\hline Count (cells $/ \mu \mathrm{L})$, median (IQR) & $1410(1060-1860)$ & $1300(1000-1790)$ & $1420(1070-1860)$ & 0.251 \\
\hline Relative count (\%), median (IQR) & $20.6(15.3-25.6)$ & $18.0(12.4-23.1)$ & $21.2(15.7-26.1)$ & 0.015 \\
\hline $\begin{array}{l}\text { Lymphocyte-to-monocyte ratio, } \\
\text { median (IQR) }\end{array}$ & $2.4(1.7-3.2)$ & $2.0(1.4-2.6)$ & $2.4(1.8-3.3)$ & 0.001 \\
\hline \multicolumn{5}{|l|}{ Discharge medication } \\
\hline ACEi, $n(\%)$ & $265(67.9)$ & $26(51.0)$ & $239(70.5)$ & 0.015 \\
\hline ARA, $n(\%)$ & $52(13.3)$ & $5(9.8)$ & 47 (13.9) & 0.478 \\
\hline Spironolactone, $n$ (\%) & $102(26.2)$ & $11(21.6)$ & $91(26.8)$ & 0.506 \\
\hline Beta-blocker, $n$ (\%) & $310(79.5)$ & $31(60.8)$ & $279(82.3)$ & 0.002 \\
\hline Nitrates, $n(\%)$ & $102(26.2)$ & $12(23.5)$ & $90(26.5)$ & 0.708 \\
\hline Statins, $n(\%)$ & $250(64.1)$ & $29(56.9)$ & $221(65.2)$ & 0.360 \\
\hline Diuretic, $n(\%)$ & $367(94.1)$ & $47(92.2)$ & $320(94.4)$ & 0.897 \\
\hline
\end{tabular}


history of arterial hypertension, a higher BNP, lower hemoglobin levels, and lower GFR values upon discharge. The prescription of angiotensin-converting enzyme inhibitor and beta-blockers showed to have a significant protective effect in both models. Besides the predictors indicated for HF death, aging, the presence of chronic renal dysfunction, and higher CRP values were also found to be significant indicators of all-cause death. Higher leukocyte and monocyte counts showed a univariate significant prognostic value for HF and all-cause death. The same univariate value was observed for lower relative lymphocyte counts, as well as lower values of LMR.

For the variables with prognostic statistical value in a univariate approach, the optimal cut-off values based on the ROC curves and Youden index were determined. The cut-off values for both endpoints are presented in Table 3. For monocyte counts and LMR, the cut-off values were the same for both the endpoints, 570 and 2.0 cells $/ \mu \mathrm{L}$, respectively. However, the cut-off values were slightly different between HF death and all-cause death for leukocytes $(10,970$ and 10,400 cells $/ \mu \mathrm{L})$ and relative lymphocytes (17.6\% and $17.8 \%$ ).

In the multivariate-adjusted models for predicting outcome, all the variables tested in continuous analysis, excluding relative lymphocytes for HF death, were independently significant of other prognostic predictors. When divided by the cut-off value, all variables maintained a significantly independent prognostic value. However, only relative lymphocytes for all-cause death $(0.96,95 \% \mathrm{CI}$ : 0.93-1.00 vs. $1.86,95 \% \mathrm{CI}: 1.09-3.18)$ and LMR for both endpoints had a higher hazard ratio (HR) than the one in the continuous analysis. In fact, when divided by the cutoff value, LMR revealed significantly adjusted HRs of 2.28 (95\% CI: 1.25-4.15) and 2.39 (95\% CI: 1.39-4.10), for 6-

Table 2 Univariate Cox-regression between patients' characteristics and 6-month heart failure and all-cause mortality, after an acute heart failure episode.

\begin{tabular}{|c|c|c|c|c|}
\hline & \multicolumn{2}{|l|}{ HF death $(n=51)$} & \multicolumn{2}{|c|}{ All-cause death $(n=66)$} \\
\hline & $\mathrm{HR}(95 \% \mathrm{CI})$ & $p$ Value & $\mathrm{HR}(95 \% \mathrm{CI})$ & $p$ Value \\
\hline \multicolumn{5}{|l|}{ Clinical characteristics, all patients $(n=390)$} \\
\hline Age (per year) & $1.00(1.00-1.01)$ & 0.072 & $1.03(1.00-1.05)$ & 0.033 \\
\hline Male sex & $1.42(0.81-2.48)$ & 0.211 & $1.08(0.67-1.75)$ & 0.747 \\
\hline Ischemic etiology of HF & $1.27(1.05-1.54)$ & 0.012 & $1.24(1.03-1.49)$ & 0.020 \\
\hline Preserved LVSF & $1.54(0.85-2.79)$ & 0.154 & $0.96(0.59-1.56)$ & 0.862 \\
\hline NYHA class at discharge (III \& IV vs. I \& II) & $1.33(1.09-1.62)$ & 0.004 & $1.31(1.10-1.56)$ & 0.002 \\
\hline \multicolumn{5}{|l|}{ Comorbidities } \\
\hline Diabetes mellitus & $0.90(0.68-1.19)$ & 0.446 & $0.84(0.66-1.08)$ & 0.182 \\
\hline Anemia history & $0.98(0.73-1.31)$ & 0.891 & $1.11(0.94-1.31)$ & 0.230 \\
\hline Chronic arterial hypertension & $0.46(0.26-0.82)$ & 0.008 & $0.47(0.28-0.79)$ & 0.004 \\
\hline Chronic renal dysfunction & $1.10(0.89-1.36)$ & 0.386 & $1.23(1.08-1.39)$ & 0.002 \\
\hline Smoking habits & $1.13(0.92-1.37)$ & 0.240 & $1.07(0.88-1.30)$ & 0.519 \\
\hline Alcohol habits & $0.89(0.51-1.55)$ & 0.673 & $0.75(0.46-1.24)$ & 0.262 \\
\hline \multicolumn{5}{|l|}{ Laboratory at discharge } \\
\hline Hemoglobin (per g/dL) & $0.84(0.73-0.98)$ & 0.023 & $0.82(0.72-0.94)$ & 0.003 \\
\hline GFR (per $\mathrm{mL} / \mathrm{min}$ ) & $0.98(0.97-1.00)$ & 0.041 & $0.98(0.97-1.00)$ & 0.011 \\
\hline $\mathrm{BNP}($ per 100 pg/mL) & $1.02(1.01-1.03)$ & $<0.000$ & $1.02(1.01-1.02)$ & $<0.000$ \\
\hline CRP (per $10 \mathrm{mg} / \mathrm{L}$ ) & $1.08(0.99-1.16)$ & 0.069 & $1.08(1.02-1.16)$ & 0.014 \\
\hline \multicolumn{5}{|l|}{ Leukocytes } \\
\hline Count (per 1000 cells $/ \mu \mathrm{L}$ ) & $1.08(1.02-1.15)$ & 0.006 & $1.08(1.02-1.14)$ & 0.006 \\
\hline \multicolumn{5}{|l|}{ Monocytes } \\
\hline Count (per 100 cells $/ \mu \mathrm{L}$ ) & $1.13(1.04-1.22)$ & 0.003 & $1.11(1.03-1.19)$ & 0.005 \\
\hline Relative count (per \%) & $1.04(0.95-1.14)$ & 0.402 & $1.03(0.95-1.12)$ & 0.497 \\
\hline \multicolumn{5}{|l|}{ Lymphocytes } \\
\hline Count (per 100 cells $/ \mu \mathrm{L}$ ) & $0.99(0.95-1.03)$ & 0.545 & $0.98(0.94-1.02)$ & 0.260 \\
\hline Relative count (per \%) & $0.96(0.92-0.99)$ & 0.020 & $0.95(0.92-0.99)$ & 0.004 \\
\hline Lymphocyte-to-monocyte ratio (per unit) & $0.69(0.52-0.91)$ & 0.010 & $0.68(0.53-0.88)$ & 0.003 \\
\hline \multicolumn{5}{|l|}{ Discharge medication } \\
\hline ACEi & $0.51(0.29-0.89)$ & 0.018 & $0.54(0.33-0.88)$ & 0.014 \\
\hline ARA & $0.70(0.28-1.77)$ & 0.452 & $0.76(0.34-1.66)$ & 0.484 \\
\hline Spironolactone & $0.77(0.39-1.50)$ & 0.443 & $0.81(0.46-1.45)$ & 0.479 \\
\hline Beta-blocker & $0.40(0.22-0.71)$ & 0.002 & $0.51(0.30-0.86)$ & 0.012 \\
\hline Nitrates & $0.83(0.49-1.42)$ & 0.506 & $0.86(0.55-1.34)$ & 0.509 \\
\hline Statins & $0.77(0.43-1.35)$ & 0.358 & $0.80(0.48-1.33)$ & 0.389 \\
\hline Diuretic & $0.85(0.41-1.75)$ & 0.655 & $0.89(0.51-1.55)$ & 0.691 \\
\hline
\end{tabular}

HR: hazard ratio; IQR: interquartile range; HF: heart failure; LVSF: left ventricular systolic function; LVSD: left ventricular systolic dysfunction; NYHA: New York Heart Association; GFR: estimated glomerular filtration rate; BNP: B-type natriuretic peptide; CRP: C-reactive protein; ACEi: angiotensin-converting enzyme inhibitor; ARA: angiotensin II receptor antagonist; $p$ value significance lower than 0.05 (95\% CI). 
Table 3 Values of area under the ROC curve (AUC), sensitivity, and specificity for the optimal cut-off for the Youden index.

\begin{tabular}{|c|c|c|c|c|c|c|c|c|}
\hline & \multicolumn{4}{|l|}{ HF death } & \multicolumn{4}{|c|}{ All-cause death } \\
\hline & Cut-off & $\begin{array}{l}\text { Sensitivity } \\
(\%)\end{array}$ & $\begin{array}{l}\text { Specificity } \\
(\%)\end{array}$ & AUC & Cut-off & $\begin{array}{l}\text { Sensitivity } \\
(\%)\end{array}$ & $\begin{array}{l}\text { Specificity } \\
(\%)\end{array}$ & AUC \\
\hline Leukocytes count (cells/ $\mu \mathrm{L}$ ) & $>10,970$ & 22 & 92 & 0.560 & $>10,400$ & 24 & 89 & 0.564 \\
\hline Monocytes count (cells/ $\mu \mathrm{L})$ & $>570$ & 69 & 52 & 0.609 & $>570$ & 64 & 52 & 0.587 \\
\hline Lymphocytes relative count (\%) & $\leq 17.6$ & 49 & 69 & 0.606 & $\leq 17.8$ & 50 & 69 & 0.614 \\
\hline Lymphocyte-to-monocyte ratio & $\leq 2.0$ & 61 & 66 & 0.643 & $\leq 2.0$ & 59 & 67 & 0.646 \\
\hline
\end{tabular}

HF: heart failure; AUC: area under the curve.

month HF and all-cause mortality, respectively. The multivariate-adjusted models and HR of 6-month HF and all-cause mortality are shown in Table 4.

Estimates clearly revealed a significantly higher risk of death, by HF or other causes, in patients with lower values of LMR upon discharge. Fig. 1 shows the survival curves estimator for the 6-month period, based on the LMR cutoff values (1.7) for HF and all-cause death.

Although no major difference was noted between the clinical characteristics of patient groups, patients with lower LMR values showed significantly higher values of BNP and CRP. They also showed significantly higher values of leukocyte and monocyte counts, but lymphocyte counts were significantly reduced. These patients also exhibited to be more prompt to have chronic renal dysfunction and lower levels of hemoglobin at discharge. Of the 51 patients who died because of HF, 22 had lower LMR values (Table 5).

\section{Discussion}

We report that upon discharge from an acute HF episode, LMR $<2.0$ is a strong predictor of unfavorable outcome. Even after adjustment for commonly predictive risk factors and confounders, a lower LMR represented approximately 2.3-fold increased risk of 6-month HF and all-cause death. To our knowledge, this is the first study that describes this association in HF patients. This is even more relevant as one of the currently identified limitations in the handling of HF patients relates to the prediction of disease evolution and severity.

The leukocyte differential is easily assessable, and it represents a potentially and weakly explored tool in $\mathrm{HF}$ prognostics and management. An association between high leukocyte count and risk factors related to the development of HF, such as coronary heart disease, myocardial infarction, and stroke, has been observed [13-15]. Other comorbidities found in HF patients, such as diabetes [16] and weight gain [17], have also been associated with high leukocyte count. In middle-aged men, an association with increased long-term incidence of $\mathrm{HF}$ hospitalizations was also described [18]. Therefore, the relationship between high leukocyte count and HF can be mediated by the incidence of risk factors commonly associated with this condition. In fact, high leukocyte count can be an important earlier risk marker for many individuals. Nevertheless, in our group of patients,

Table 4 Multivariate Cox-regression model on 6-month HF death and all-cause mortality, after an acute HF episode.

\begin{tabular}{|c|c|c|c|c|}
\hline & \multicolumn{2}{|l|}{ HF death ${ }^{a}$} & \multicolumn{2}{|l|}{ All-cause death $^{\mathrm{b}}$} \\
\hline & $\mathrm{HR}(95 \% \mathrm{CI})$ & $p$ Value & $\operatorname{HR}(95 \% \mathrm{CI})$ & $p$ Value \\
\hline \multicolumn{5}{|l|}{ Leukocytes } \\
\hline Count (per 1000 cells $/ \mu \mathrm{L}$ ) & $1.09(1.02-1.15)$ & 0.006 & $1.08(1.02-1.15)$ & 0.009 \\
\hline Count (cut-off value) & $0.37(0.18-0.79)$ & 0.009 & $0.43(0.22-0.83)$ & 0.012 \\
\hline \multicolumn{5}{|l|}{ Monocytes } \\
\hline Count (per 100 cells $/ \mu \mathrm{L}$ ) & $1.12(1.03-1.21)$ & 0.009 & $1.12(1.03-1.21)$ & 0.005 \\
\hline Count (cut-off value) & $0.48(0.26-0.89)$ & 0.021 & $0.47(0.28-0.84)$ & 0.011 \\
\hline \multicolumn{5}{|l|}{ Lymphocytes } \\
\hline Relative count (per \%) & $0.96(0.93-1.00)$ & 0.063 & $0.96(0.93-1.00)$ & 0.044 \\
\hline Relative count (cut-off value) & - & & $1.86(1.09-3.18)$ & 0.024 \\
\hline Lymphocyte-to-monocyte ratio (per unit) & $0.72(0.53-0.98)$ & 0.038 & $0.72(0.55-0.95)$ & 0.019 \\
\hline Lymphocyte-to-monocyte ratio (cut-off value) & $2.28(1.25-4.15)$ & 0.007 & $2.39(1.39-4.10)$ & 0.002 \\
\hline
\end{tabular}

HR: hazard ratio; HF: heart failure; $p$ value significance lower than 0.05 (95\% CI).

${ }^{\text {a }}$ Model adjusted for: Ischemic etiology of heart failure; New York Heart Association class at discharge (III \& IV vs. I \& II); Chronic arterial hypertension; Hemoglobin (per g/dL); Estimated glomerular filtration rate; B-type natriuretic peptide (per $100 \mathrm{pg} / \mathrm{mL}$ ); Angiotensin-converting enzyme inhibitor; Beta-blocker medication.

b Model adjusted for: Age (per year); Ischemic etiology of heart failure; New York Heart Association class at discharge (III \& IV vs. I \& II); Chronic arterial hypertension; Chronic renal dysfunction; Hemoglobin (per g/dL); Estimated glomerular filtration rate; B-type natriuretic peptide (per $100 \mathrm{pg} / \mathrm{mL}$ ); C-reactive protein (per $10 \mathrm{mg} / \mathrm{L}$ ); Angiotensin-converting enzyme inhibitor; Beta-blocker medication. 

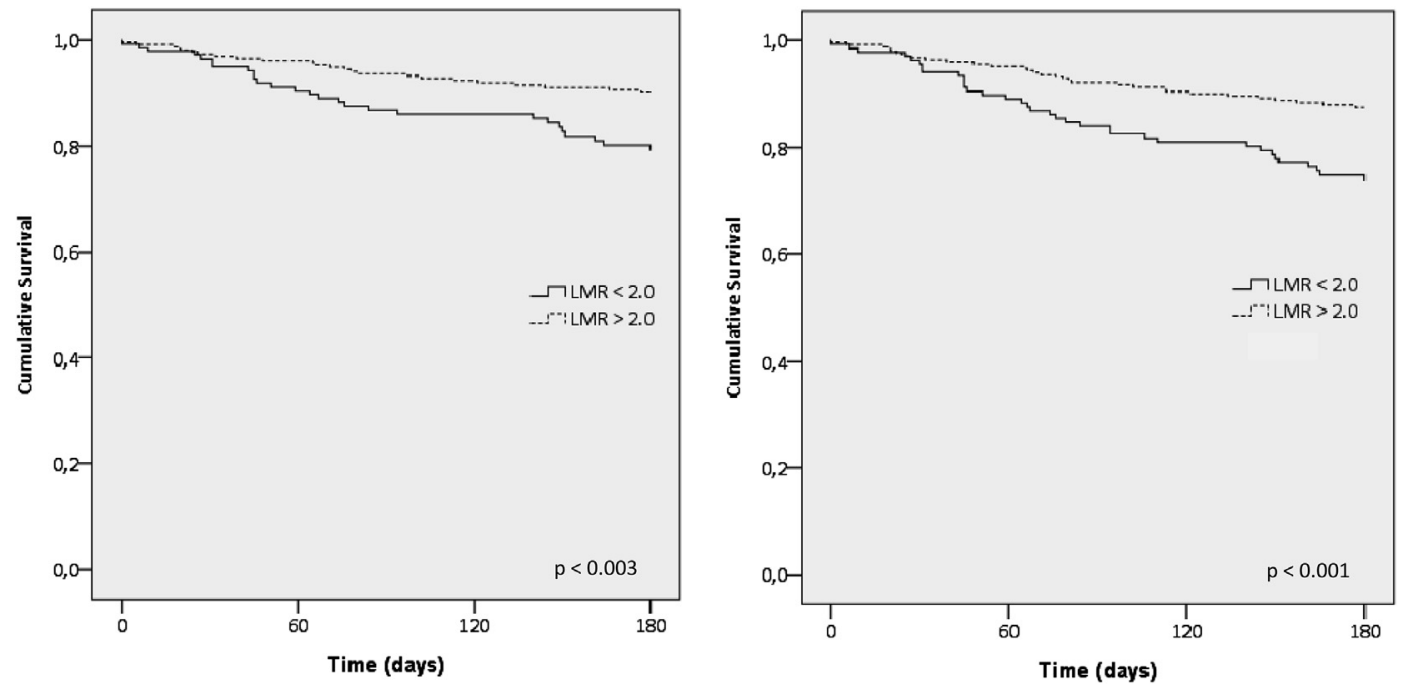

Figure 1 Kaplan-Meier survival curves according to lymphocyte-to-monocyte ratio cut-off values of 2.0. Left: heart failure death endpoint; Right: all-cause death endpoint. Patients with lower values of lymphocyte-to-monocyte ratio had a higher 6-month risk of death for both endpoints after an acute heart failure episode. LMR: lymphocyte-to-monocyte ratio.

leukocyte count showed a significant prognostic value for both endpoints, independent of other common risk factors such as ischemic etiology and history of hypertension. For $\mathrm{HF}$ and all-cause death, the HRs were 1.09 and 1.08 , respectively, for each 1000 cells $/ \mu \mathrm{L}$ increase.

Individual leukocyte subpopulations represent single elements of the leukocyte differential and immunological processes. In patients with HF, lower relative lymphocyte counts have been associated with worse outcomes [19-22]. It is also evident from our study that lower relative lymphocyte counts were associated with all-cause death and a trend to predict HF death. However, when divided by quartiles, these counts did not retain a significant predictive value. Availability of limited data regarding monocytes shows conflicting results. In patients with an existing diagnosis of HF, increased monocyte count was found to be associated with HF and unfavorable outcomes $[23,24]$. However, the Atherosclerosis Risk in Communities (ARIC) study found no association between monocyte count and HF [15]. Our data corroborates the findings associated with unfavorable outcomes, since in our group of patients, a higher monocyte count ( $>770$ cells $/ \mathrm{mL}$ ) independently indicated a higher risk of HF and all-cause death.

The LMR is determined from the counts of lymphocytes and monocytes, two different cells included in the leukocyte differential. Relative lymphopenia reflects a physiologic stress response, whereas monocytosis reflects a chronic systemic inflammation. It has been found recently that a low LMR is associated with a high mortality in patients with malignant hematologic disorders [25-27] and atherosclerotic disease [28]. In recent years, activation of the immune system and inflammation have been well characterized in HF, being now certain that they play important roles in this condition [29-32]. It has also been shown that lymphocytes and monocytes can be activated by proinflammatory cytokines [33-35]. This activation converts the cells into potential sources of proinflammatory cytokines that lead to further activation of these cells, contributing to the systemic inflammation in HF patients. High circulating levels of proinflammatory cytokines may have several adverse effects in patients with $\mathrm{HF}$, including myocardial remodeling, promotion of cardiac arrhythmia, and negative inotropy [36,37]. The most acceptable hypothesis for mediators that can activate this response, especially in acute episodes of HF, is bacterial endotoxin translocation due to intestinal bacterial proliferation. Several studies indicate that during repetitive episodes of decompensation, particularly when associated with severe systemic congestion, bacterial endotoxin translocation may occur from the gut into circulation. This translocation would activate lymphocytes and monocytes with the consequent release of proinflammatory cytokines [38-41]. This hypothesis clarifies our results in LMR. The approximately 2.5-fold higher risk of death found in our study may reflect the endotoxin translocation and immune activation of lymphocytes and monocytes. This activation will result in higher counts of these cells and subsequent lower LMR values, representative of a higher risk group of patients.

The main objective of this study was to evaluate if LMR could successfully discriminate patients at a higher risk of death, independently of standard risk predictors. To our knowledge, this is the first study that strongly establishes a significant role of LMR as a predictor marker of mortality in an adjusted survival model.

In order to clarify whether these low values of LMR are directly involved in the pathogenesis of HF or whether they are just a marker of disease severity, further research is needed to be conducted. The limitation of this study is its inability to reveal the exact pathophysiologic mechanisms hidden behind LMR. Alongside with this limitation, we also acknowledge that this is a single-center study with all the well-known bias and inherent confounding. For this reason, an external validation by an independent cohort must be the first step in investigations to safely establish 
Table 5 Patients' demographics, clinical and laboratory characteristics, and discharge medication according to the LMR cut-off value.

\begin{tabular}{|c|c|c|c|}
\hline & Low LMR $(n=95)$ & High LMR $(n=295)$ & $p$ Value \\
\hline \multicolumn{4}{|l|}{ Clinical characteristics } \\
\hline Age (years), median (IQR) & $78(72-84)$ & $78(69-84)$ & 0.358 \\
\hline Male sex, $n(\%)$ & $51(53.7)$ & $137(46.6)$ & 0.230 \\
\hline Ischemic etiology of $\mathrm{HF}, n(\%)$ & 36 (37.9) & $102(34.7)$ & 0.630 \\
\hline Preserved LVSF, $n(\%)$ & $42(44.2)$ & $121(41.2)$ & 0.650 \\
\hline NYHA class at discharge (III \& IV vs. I \& II), $n(\%)$ & $22(23.2)$ & $53(18.0)$ & 0.230 \\
\hline \multicolumn{4}{|l|}{ Comorbidities } \\
\hline Diabetes mellitus, $n(\%)$ & $43(45.3)$ & $128(43.5)$ & 0.768 \\
\hline Anemia history, $n(\%)$ & $46(48.4)$ & $121(41.2)$ & 0.500 \\
\hline Chronic arterial hypertension, $n(\%)$ & $74(77.9)$ & $225(76.5)$ & 0.962 \\
\hline Chronic renal dysfunction, $n(\%)$ & $29(30.5)$ & $60(20.4)$ & 0.067 \\
\hline \multicolumn{4}{|l|}{ Smoking habits, $n(\%)$} \\
\hline Current smoker/ex-smoker & $11 / 30(11.6 / 31.6)$ & $20 / 80(6.8 / 27.2)$ & 0.235 \\
\hline Alcohol habits, $n(\%)$ & $49(51.6)$ & $129(43.9)$ & 0.218 \\
\hline \multicolumn{4}{|l|}{ Laboratory at discharge } \\
\hline Hemoglobin (g/dL), median (IQR) & $11.8(10.9-12.7)$ & $12.1(10.8-13.7)$ & 0.077 \\
\hline GFR (mL/min), median (IQR) & $34.4(25.8-50.7)$ & $40.0(29.7-52.4)$ & 0.198 \\
\hline $\mathrm{BNP}(\mathrm{pg} / \mathrm{mL})$, median $(\mathrm{IQR})$ & $871.6(451.2-1633.9)$ & $657.9(262.9-1307.3)$ & 0.007 \\
\hline CRP (mg/L), median (IQR) & $15.5(8.2-36.5)$ & $11.1(5.5-24.6)$ & 0.005 \\
\hline \multicolumn{4}{|l|}{ Leukocytes } \\
\hline Count (cells/ $\mu \mathrm{L}$ ), median (IQR) & $7690(6030-9720)$ & $7085(5785-8485)$ & 0.049 \\
\hline \multicolumn{4}{|l|}{ Monocytes } \\
\hline Count (cells $/ \mu \mathrm{L}$ ), median (IQR) & $780(590-1010)$ & $540(430-700)$ & $<0.000$ \\
\hline Relative count (\%), median (IQR) & $10.6(8.1-12.4)$ & $8.0(6.6-9.6)$ & $<0.000$ \\
\hline \multicolumn{4}{|l|}{ Lymphocytes } \\
\hline Count (cells/ $\mu \mathrm{L}$ ), median (IQR) & $1010(720-1330)$ & $1580(1198-2043)$ & $<0.000$ \\
\hline Relative count (\%), median (IQR) & $13.6(9.5-17.8)$ & $22.8(18.8-27.3)$ & $<0.000$ \\
\hline Lymphocyte-to-monocyte ratio, median (IQR) & $1.4(1.1-1.6)$ & $2.7(2.2-3.6)$ & $<0.000$ \\
\hline \multicolumn{4}{|l|}{ Discharge medication } \\
\hline ACEi, $n(\%)$ & $59(62.1)$ & $205(69.7)$ & 0.141 \\
\hline ARA, $n(\%)$ & $11(11.6)$ & $41(13.9)$ & 0.541 \\
\hline Spironolactone, $n(\%)$ & $22(23.2)$ & 79 (26.9) & 0.453 \\
\hline Beta-blocker, $n$ (\%) & $70(73.7)$ & $239(81.3)$ & 0.085 \\
\hline Nitrates, $n(\%)$ & $26(27.4)$ & 76 (25.9) & 0.769 \\
\hline Statins, $n(\%)$ & $65(68.4)$ & $185(62.9)$ & 0.282 \\
\hline Diuretic, $n(\%)$ & 89 (93.7) & $277(94.2)$ & 0.698 \\
\hline HF death & $22(23.3)$ & $29(9.9)$ & 0.001 \\
\hline All-cause death & $29(30.5)$ & $37(12.6)$ & $<0.000$ \\
\hline
\end{tabular}

and confirm the potential use of this ratio in predicting $\mathrm{HF}$ outcomes. Nevertheless, our main goal was to demonstrate that LMR is an easily obtained, widely available, and inexpensive tool that can be used in the risk stratification between HF patients with high and low risk of death, in addition to the traditionally used markers.

\section{Conclusion}

Our results show that upon discharge from hospital after an episode of acute HF, LMR $<2.0$ is associated with an approximately 2.3-fold higher risk of 6-month HF and allcause mortality. Our results suggest that this ratio may have a role in the identification of patients with increased risk of mortality.

\section{Acknowledgment}

This work was supported by Portuguese Foundation for Science and Technology (SFRH/BD/79716/2011 and PIC/IC/ 82773/2007).

\section{References}

[1] Rocchiccioli JP, McMurray JJ, Dominiczak AF. Biomarkers in heart failure: a clinical review. Heart Fail Rev 2010;15(4):251-73. http: //dx.doi.org/10.1007/s10741-008-9123-9.

[2] Gong KZ, Song G, Spiers JP, Kelso EJ, Zhang ZG. Activation of immune and inflammatory systems in chronic heart failure: novel therapeutic approaches. Int J Clin Pract 2007;61(4):611-21. http: //dx.doi.org/10.1111/j.1742-1241.2007.01295.x.

[3] Apostolakis S, Lip GY, Shantsila E. Monocytes in heart failure: relationship to a deteriorating immune overreaction or a 
desperate attempt for tissue repair? Cardiovasc Res 2010;85(4): 649-60. http://dx.doi.org/10.1093/cvr/cvp327.

[4] Vasan RS, Sullivan LM, Roubenoff R, Dinarello CA, Harris T, Benjamin EJ, et al. Inflammatory markers and risk of heart failure in elderly subjects without prior myocardial infarction: the Framingham heart study. Circulation 2003;107(11):1486-91.

[5] Kardys I, Knetsch AM, Bleumink GS, Deckers JW, Hofman A, Stricker BH, et al. C-reactive protein and risk of heart failure. The Rotterdam study. Am heart J 2006;152(3):514-20. http: //dx.doi.org/10.1016/j.ahj.2006.02.023.

[6] Gottdiener JS, Arnold AM, Aurigemma GP, Polak JF, Tracy RP, Kitzman DW, et al. Predictors of congestive heart failure in the elderly: the cardiovascular health study. J Am Coll Cardiol 2000; 35(6):1628-37.

[7] Suzuki T, Katz R, Jenny NS, Zakai NA, LeWinter MM, Barzilay JI, et al. Metabolic syndrome, inflammation, and incident heart failure in the elderly: the cardiovascular health study. Circ Heart Fail 2008; 1(4):242-8. http://dx.doi.org/10.1161/circheartfailure.108.785485.

[8] Burchfield JS, Xie M, Hill JA. Pathological ventricular remodeling: mechanisms: part 1 of 2 . Circulation 2013;128(4):388-400. http: //dx.doi.org/10.1161/circulationaha.113.001878.

[9] Kania G, Blyszczuk P, Eriksson U. Mechanisms of cardiac fibrosis in inflammatory heart disease. Trends Cardiovasc Med 2009;19(8): 247-52. http://dx.doi.org/10.1016/j.tcm.2010.02.005.

[10] Wei L. Immunological aspect of cardiac remodeling: T lymphocyte subsets in inflammation-mediated cardiac fibrosis. Exp Mol Pathol 2011;90(1):74-8. http://dx.doi.org/10.1016/j.yexmp.2010.10.004.

[11] Dickstein K, Cohen-Solal A, Filippatos G, McMurray JJ, Ponikowski P, Poole-Wilson PA, et al. ESC guidelines for the diagnosis and treatment of acute and chronic heart failure 2008: the Task Force for the diagnosis and treatment of acute and chronic heart failure 2008 of the European Society of Cardiology. Developed in collaboration with the Heart Failure Association of the ESC (HFA) and endorsed by the European Society of Intensive Care Medicine (ESICM). Eur J Heart Fail 2008;10(10):933-89. http: //dx.doi.org/10.1016/j.ejheart.2008.08.005.

[12] Cockcroft DW, Gault MH. Prediction of creatinine clearance from serum creatinine. Nephron 1976;16(1):31-41.

[13] Wilhelmsen L, Rosengren A, Eriksson H, Lappas G. Heart failure in the general population of men - morbidity, risk factors and prognosis. J Intern Med 2001;249(3):253-61.

[14] Pfister R, Sharp SJ, Luben R, Wareham NJ, Khaw KT. Differential white blood cell count and incident heart failure in men and women in the EPIC-Norfolk study. Eur Heart J 2012;33(4):523-30. http://dx.doi.org/10.1093/eurheartj/ehr457.

[15] Bekwelem W, Lutsey PL, Loehr LR, Agarwal SK, Astor BC, Guild C, et al. White blood cell count, C-reactive protein, and incident heart failure in the atherosclerosis risk in communities (ARIC) study. Ann Epidemiol 2011;21(10):739-48. http: //dx.doi.org/10.1016/j.annepidem.2011.06.005.

[16] Schmidt MI, Duncan BB, Sharrett AR, Lindberg G, Savage PJ, Offenbacher $\mathrm{S}$, et al. Markers of inflammation and prediction of diabetes mellitus in adults (atherosclerosis risk in communities study): a cohort study. Lancet 1999;353(9165): $1649-52$.

[17] Engstrom G, Hedblad B, Stavenow L, Lind P, Janzon L, Lindgarde F. Inflammation-sensitive plasma proteins are associated with future weight gain. Diabetes 2003;52(8):2097-101.

[18] Engstrom G, Melander O, Hedblad B. Leukocyte count and incidence of hospitalizations due to heart failure. Circ Heart Fail 2009;2(3): 217-22. http://dx.doi.org/10.1161/circheartfailure.108.827071.

[19] Acanfora D, Gheorghiade M, Trojano L, Furgi G, Pasini E, Picone C, et al. Relative lymphocyte count: a prognostic indicator of mortality in elderly patients with congestive heart failure. Am Heart J 2001;142(1):167-73.

[20] Levy WC, Mozaffarian D, Linker DT, Sutradhar SC, Anker SD, Cropp $A B$, et al. The Seattle heart failure model: prediction of survival in heart failure. Circulation 2006;113(11):1424-33. http: //dx.doi.org/10.1161/circulationaha.105.584102.

[21] Vaduganathan M, Ambrosy AP, Greene SJ, Mentz RJ, Subacius HP, Maggioni AP, et al. Predictive value of low relative lymphocyte count in patients hospitalized for heart failure with reduced ejection fraction: insights from the EVEREST trial. Circ Heart Fail 2012;5(6):750-8. http://dx.doi.org/10.1161/circheartfailure.112.97 0525.
[22] Nunez J, Nunez E, Minana G, Sanchis J, Bodi V, Rumiz E, et al. Effectiveness of the relative lymphocyte count to predict one-year mortality in patients with acute heart failure. Am J Cardiol 2011; 107(7):1034-9. http://dx.doi.org/10.1016/j.amjcard.2010.11.029.

[23] Dixon DL, Griggs KM, Bersten AD, De Pasquale CG. Systemic inflammation and cell activation reflects morbidity in chronic heart failure. Cytokine 2011;56(3):593-9. http: //dx.doi.org/10.1016/j.cyto.2011.08.029.

[24] Shantsila E, Bialiuk N, Navitski D, Pyrochkin A, Gill PS, Pyrochkin V, et al. Blood leukocytes in heart failure with preserved ejection fraction: impact on prognosis. Int J Cardiol 2012;155(2):337-8. http://dx.doi.org/10.1016/j.ijcard.2011.12.048.

[25] Porrata LF, Ristow K, Colgan JP, Habermann TM, Witzig TE, Inwards DJ, et al. Peripheral blood lymphocyte/monocyte ratio at diagnosis and survival in classical Hodgkin's lymphoma. Haematologica 2012; 97(2):262-9. http://dx.doi.org/10.3324/haematol.2011.050138.

[26] Li ZM, Huang JJ, Xia Y, Sun J, Huang Y, Wang Y, et al. Blood lymphocyte-to-monocyte ratio identifies high-risk patients in diffuse large B-cell lymphoma treated with R-CHOP. PLoS One 2012; 7(7):e41658. http://dx.doi.org/10.1371/journal.pone.0041658.

[27] Watanabe R, Tomita N, Itabashi M, Ishibashi D, Yamamoto E, Koyama S, et al. Peripheral blood absolute lymphocyte/monocyte ratio as a useful prognostic factor in diffuse large B-cell lymphoma in the rituximab era. Eur J Haematol 2014;92(3):204-10. http: //dx.doi.org/10.1111/ejh.12221.

[28] Gary T, Pichler M, Belaj K, Eller P, Hafner F, Gerger A, et al. Lymphocyte-to-monocyte ratio: a novel marker for critical limb ischemia in PAOD patients. Int J Clin Pract 2014;68(12):1483-7. http://dx.doi.org/10.1111/ijcp.12495.

[29] Torre-Amione G. Immune activation in chronic heart failure. Am J Cardiol 2005;95(11a):3C-8C. http://dx.doi.org/10.1016/j.amjcard.2005.03.006. discussion 38C-40C.

[30] von Haehling S, Schefold JC, Lainscak M, Doehner W, Anker SD. Inflammatory biomarkers in heart failure revisited: much more than innocent bystanders. Heart Fail Clin 2009;5(4):549-60. http: //dx.doi.org/10.1016/j.hfc.2009.04.001.

[31] Gruson D, Ahn SA, Rousseau MF. Biomarkers of inflammation and cardiac remodeling: the quest of relevant companions for the risk stratification of heart failure patients is still ongoing. Biochem Med 2011;21(3):254-63.

[32] Lourenco P, Paulo Araujo J, Paulo C, Mascarenhas J, Frioes F, Azevedo A, et al. Higher C-reactive protein predicts worse prognosis in acute heart failure only in noninfected patients. Clin Cardiol 2010;33(11):708-14. http://dx.doi.org/10.1002/clc.20812.

[33] Fildes JE, Shaw SM, Yonan N, Williams SG. The immune system and chronic heart failure: is the heart in control? J Am Coll Cardiol 2009;53(12):1013-20. //dx.doi.org/10.1016/j.jacc.2008.11.046.

[34] Yndestad A, Damas JK, Oie E, Ueland T, Gullestad L, Aukrust P. Systemic inflammation in heart failure - the whys and wherefores. Heart Fail Rev 2006;11(1):83-92. http: //dx.doi.org/10.1007/s10741-006-9196-2.

[35] Tamariz L, Hare JM. Inflammatory cytokines in heart failure: roles in aetiology and utility as biomarkers. Eur Heart J 2010;31(7): 768-70. http://dx.doi.org/10.1093/eurheartj/ehq014.

[36] Prabhu SD. Cytokine-induced modulation of cardiac function. Circ Res 2004;95(12):1140-53. http://dx.doi.org/10.1161/01.res.0000 150734.79804.92.

[37] Korantzopoulos P, Kolettis T, Siogas K, Goudevenos J. Atrial fibrillation and electrical remodeling: the potential role of inflammation and oxidative stress. Med Sci Monit Int Med J Exp Clin Res 2003;9(9):Ra225-9.

[38] Anker SD, Egerer KR, Volk HD, Kox WJ, Poole-Wilson PA, Coats AJ. Elevated soluble CD14 receptors and altered cytokines in chronic heart failure. Am J Cardiol 1997;79(10):1426-30.

[39] Niebauer J, Volk HD, Kemp M, Dominguez M, Schumann RR, Rauchhaus M, et al. Endotoxin and immune activation in chronic heart failure: a prospective cohort study. Lancet 1999;353(9167): 1838-42. http://dx.doi.org/10.1016/s0140-6736(98)09286-1.

[40] Krack A, Sharma R, Figulla HR, Anker SD. The importance of the gastrointestinal system in the pathogenesis of heart failure. Eur Heart J 2005;26(22):2368-74. http://dx.doi.org/10.1093/eurheartj/ehi389.

[41] Andreasen AS, Krabbe KS, Krogh-Madsen R, Taudorf S, Pedersen BK, Moller K. Human endotoxemia as a model of systemic inflammation. Curr Med Chem 2008;15(17):1697-705. 